\title{
Pelatihan Pembuatan Blog Pembelajaran Bagi Guru Sekolah Dasar Punna Karya Kabupaten Tangerang
}

\author{
Suntoro*1 \\ 1Program Studi Pendidikan Profesi Guru, Jurusan Dharmacarya, \\ Sekolah Tinggi Agama Buddha Negeri Sriwijaya Tangerang \\ *e-mail: suntoro@stabn-sriwijaya.ac.id 1
}

\begin{abstract}
The aim of community service is to provide blogging skills that can be utilized by Punna Karya Tangerang elementary school teachers in learning. The service delivery method is a workshop held from November to December 2019. Evaluation of activities is carried out using non-test techniques using questionnaires and documentation. The questionnaire was used to compare teachers' understanding of creating learning blogs between before and after the training was carried out. While the documentation serves to see qualitatively a learning blog created by the teacher. The results of this community service are: (1) classically the competence of teachers in creating learning blogs increased by 85,80\%; (2) qualitatively the learning blog produced by the teacher is good, but there are still shortcomings in terms of interface design, navigation, and its contents. Based on these results teachers should be able to improve their skills independently in designing blog-based learning media through online and print references.
\end{abstract}

Keywords: teacher, blog, learning media

\begin{abstract}
Abstrak
Tujuan pengabdian kepada masyarakat ini adalah untuk memberikan keterampilan membuat blog yang dapat dimanfaatkan guru SD Punna Karya Tangerang dalam pembelajaran. Metode pelaksanaan pengabdian ialah workshop yang dilaksanakan selama bulan November hingga Desember 2019. Evaluasi kegiatan dilakukan dengan teknik nontes menggunakan kuesioner dan dokumentasi. Kuesioner digunakan untuk membandingkan pemahaman guru membuat blog pembelajaran antara sebelum dan sesudah dilaksanakan pelatihan. Sementara dokumentasi berfungsi untuk melihat secara kualitatif blog pembelajaran yang dibuat oleh guru. Hasil pengabdian masyarakat ini ialah: (1) secara klasikal kompetensi guru dalam membuat blog pembelajaran meningkat sebesar 85,80\%; (2) secara kualitatif blog pembelajaran yang dihasilkan guru sudah baik, namun masih terdapat kekurangan baik dari sisi desain interface, navigasi, maupun isinya. Berdasarkan hasil tersebut guru hendaknya dapat meningkatkan keterampilan secara mandiri dalam mendesain media pembelajaran berbasis blog melalui referensi baik daring maupun cetak.
\end{abstract}

Kata kunci: guru, blog, media pembelajaran

\section{PENDAHULUAN}

Abad XXI yang sarat dengan derasnya arus informasi, komputasi, dan automasi telah mengubah paradigma pembelajaran. Pembelajaran di kelas diarahkan untuk menumbuhkembangkan potensi yang dimiliki peserta didik dengan guru sebagai fasilitator. Pada posisi itulah guru dituntut kreatif merancang pembelajaran dan memfasilitasi siswa dalam mendapatkan pengetahuan yang bermakna. Terlebih di era informasi digital berkembang pesat seperti saat ini, seharusnya tidak ada alasan bagi guru kekurangan informasi (Suntoro, 2019: 193). Terjadinya proses belajar tidak selalu harus ada orang yang mengajar. Oleh karena itu, keberadaan orang yang mengajar dapat digantikan oleh sumber belajar lain termasuk media pembelajaran. Munadi (2013: 6-8) media pembelajaran sebagai segala sesuatu yang dapat menyampaikan dan menyalurkan pesan dari sumber secara terencana sehingga tercipta lingkungan belajar yang kondusif di mana penerimanya dapat melakukan proses belajar secara efisien dan efektif. Mengutip pendapat Munadi maka secara tidak langsung keberadaan media pembelajaran dapat menyederhanakan proses belajar. Sementara itu, Djamarah dan Zain (2006: 121) mendefinisikan media sebagai alat bantu apa saja yang dapat dijadikan sebagai penyalur pesan guna mencapai tujuan pengajaran. 
Tak bisa dipungkiri, keberadaan media pembelajaran dalam sistem pembelajaran sangat fundamental. Kedudukan media pembelajaran bahkan sejajar dengan metode pembelajaran, karena metode yang digunakan dalam proses pembelajaran biasanya akan menuntut media apa yang dapat diintegrasikan dan diadaptasikan dengan kondisi yang dihadapi. Ada banyak jenis media pembelajaran antara lain media cetak, audio, video, multimedia, dan e-learning. Salah satu media yang media e-learning yang mampu mengakomodasi sifat informatif, komputasi, dan automasi adalah blog.

Beberapa penelitian menunjukkan bahwa pemanfaatan blog sebagai media pembelajaran sangat efektif dalam meningkatkan hasil belajar siswa. Penelitian Rahman, Munawar, dan Berman (2014: 137) menunjukkan ada pengaruh penggunaan media pembelajaran blog terhadap hasil belajar kognitif siswa. Penelitian Pujiastutik (2019: 25) penggunaan media blog meningkatkan hasil belajar siswa dengan ketuntasan belajar mencapai 92\%. Tanggapan siswa terhadap pemanfaatan media e-learning berbasis blog juga positif. Tidak hanya pada jenjang dasar dan menengah, Hammudin, dkk. (2017: 54) menjelaskan bahwa mahasiswa FKIP Unilak memiliki persepsi positif dan mendukung penggunaan blog sebagai media pembelajaran peningkatan kemampuan bahasa Inggris di kelas. Selain penelitian, hasil pengabdian kepada masyarakat seperti yang dilakukan oleh Supriyono, dkk. (2015), Sartono (2016), Hasan, Rahman, dan Anis (2017), serta Taufik, dkk. (2018) dengan sasaran guru, menunjukkan bahwa website efektif digunakan dlam kegiatan pembelajaran di kelas. Berkaca pada beberapa kajian di atas, hendaknya guru mengembangkan kemampuan diri dalam membuat media pembelajaran berbasis blog.

Salah satu sekolah yang sangat tertarik pada pemanfaatan blog sebagai media pembelajaran di sekolah adalah Sekolah Dasar (SD) Punna Karya. SD Punna Karya merupakan salah satu sekolah swasta yang berada di Kabupaten Tangerang. Sekolah ini terletak di Jalan Margasari Nomor 33 Desa Curug Kulon Kecamatan Curug dan berada di bawah naungan Yayasan Punna Karya. Saat ini SD Punna Karya memiliki sekitar 150 murid dan guru sebanyak 25. Dalam menjawab tantangan pembelajaran abad ke-21, kepala sekolah sangat berharap agar guru-guru mampu menciptakan pembelajaran yang interaktif, inovatif, dan kreatif dengan memanfaatkan teknologi informasi. Berdasarkan wawancara dengan Kepala SD Punna Karya, kompetensi guru dalam menyediakan media pembelajaran yang kreatif dan inovatif bagi siswa masih masih kurang. Indikatornya adalah sebagian besar guru masih tergantung buku paket sebagai media pembelajaran utama saat mengajar. Padahal, sekolah telah menyediakan perangkat projector dan koneksi wifi yang dapat diakses di semua lingkungan sekolah. Oleh karena itu, pihak sekolah sangat berharap guru-guru SD Punna Karya mampu memanfaatkan media pembelajaran berbasis teknologi informasi dalam pembelajaran. Pemanfaatan teknologi informasi diharapkan dapat merangsang minat belajar siswa dan meningkatkan hasil belajar siswa dan dapat digunakan sebagai media belajar mandiri oleh siswa.

Untuk mengatasi permasalah tersebut, guru harus diberikan pelatihan pembuatan media pembelajaran interaktif berbasis teknologi informasi. Berdasarkan kajian beberapa penelitian terdahulu, media blog sangat efektif digunakan untuk meningkatkan kualitas pembelajaran. Oleh karena itu, pengabdian ini berusaha memberikan pendampingan kepada guru-guru di SD Punna Karya membuat blog pembelajaran dengan judul "Pelatihan Pembuatan Blog Pembelajaran bagi Guru SD Punna Karya Kabupaten Tangerang".

\section{METODE}

Metode yang digunakan dalam pengabdian kepada masyarakat ini adalah workshop. Workhsop dilakukan pada bulan November sampai Desember 2019. Peserta kegiatan ini adalah guru SD Punna Karya Kabupaten Tangerang berjumlah 11 orang. Materi workshop yang diberikan meliputi pemilihan nama domain, instalasi template, pengenalan fitur blogspot, dan menulis artikel pembelajaran. Evaluasi kegiatan pengabdian masyarakat dilakukan dengan teknik nontes yaitu dengan menggunakan kuesioner dan dokumentasi. Kuesioner digunakan 
untuk mengambil data kuantitatif dengan cara membandingkan keterampilan guru sebelum dan sesudah dilakukan pelatihan. Aspek yang dinilai meliputi: (1) memilih nama doman; (2) memahami fungsi-fungsi operasional pada blogspot; (3) instalasi template; dan (4) menulis artikel yang dijabarkan menjadi: (a) menulis judul artikel; (b) menjadwalkan penerbitan artikel secara otomatis; (c) mengaktegorikan artikel dengan label (d) menyisipkan gambar dan video pembelajaran pada artikel; (e) menautkan antarartikel dalam satu blog; dan (f) menautkan antarartikel dalam blog yang berbeda. Pengukuran menggunakan skala likert dengan skala 1 sampai 4. Pengukuran persentase peningkatan pemahaman guru membuat blog pembelajaran diukur menggunakan rumus: persentase $(\%)=(($ nilai akhir - nilai awal $) /$ nilai awal $) * 100 \%$. Sementara itu, dokumentasi digunakan untuk mengukur data kualitatif blog pembelajaran yang dibuat guru selama pelatihan. Data kualitatif blog pembelajaran meliputi: (1) isi blog; (2) navigasi; dan (3) design interface.

\section{HASIL DAN PEMBAHASAN}

Pengabdian kepada masyarakat dilakukan sebanyak dua kali yaitu pada tanggal 2 November 2019 dan 6 Desember 2019. Pada tanggal 2 November 2019 materi pelatihan yang diberikan antara lain: (1) mengenal website berbasis blogspot; (2) memilih nama doman; (3) memahami fungsi-fungsi operasional pada blogspot; (4) instalasi template; dan (5) menulis artikel pembelajaran pada blog. Pada pelatihan ke-2 tanggal 6 Desember 2019, materi pelatihan yang diberikan adalah lanjutan materi menulis artikel pada pertemuan pertama. Materi menulis artikel yang diberikan meliputi: (1) menulis judul artikel; (2) menjadwalkan penerbitan artikel secara otomatis; (3) mengaktegorikan artikel dengan label (4) menyisipkan gambar dan video pembelajaran pada artikel; (5) menautkan antarartikel dalam satu blog; dan (6) menautkan antarartikel dalam blog yang berbeda.
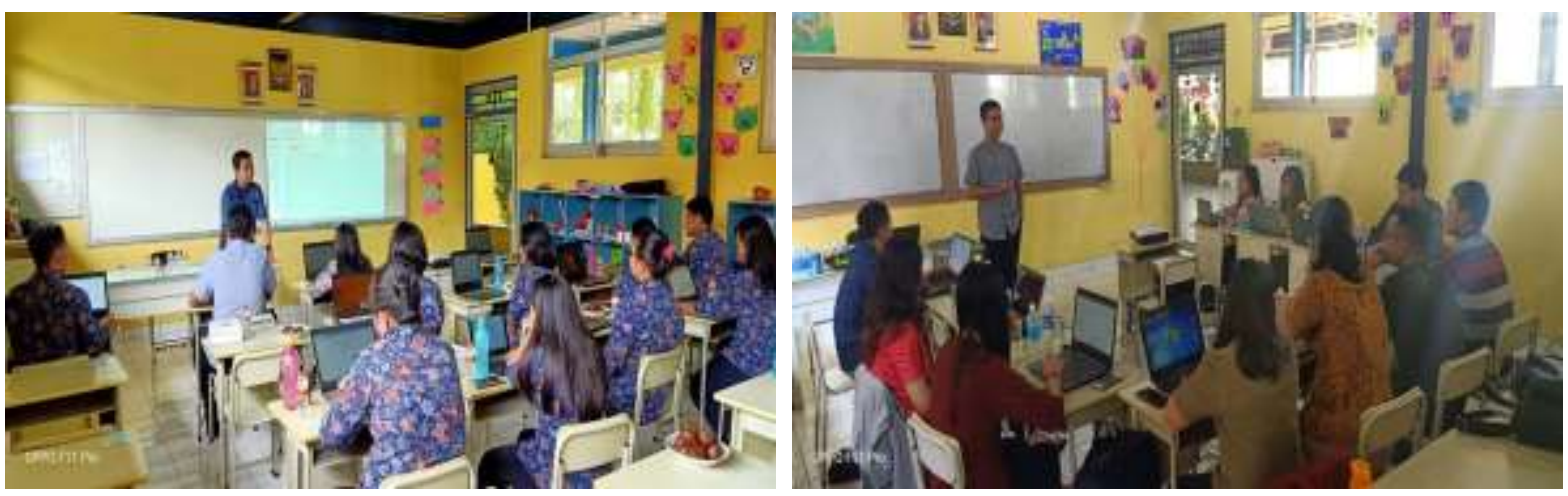

Gambar 1. Pemaparan Materi

Setelah pelatihan dihasilkan sebelas blog pembelajaran yang sesuai dengan bidang keahlian guru. Platform blogspot dipilih karena bebas biaya hosting dan domain. Berikut adalah alamat blog yang dihasilkan dari kegiatan pengabdian kepada masyarakat ini.

Tabel 1. Alamat Blog Pembelajaran

\begin{tabular}{cl}
\hline Nomor & \multicolumn{1}{c}{ Alamat Blog } \\
\hline 1. & https://punnakaryasquad.blogspot.com \\
2. & $\underline{\text { https://kelastigahebat.blogspot.com }}$ \\
3. & $\underline{\text { https://punnakaryahappy.blogspot.com }}$ \\
4. & $\underline{\text { https://gurupunnakarya.blogspot.com }}$ \\
5. & $\underline{\mathrm{https}: / / \text { belajarsigap.blogspot.com }}$ \\
6. & $\underline{\mathrm{https}: / / \text { sinaudhamma.blogspot.com }}$ \\
7. & $\underline{\mathrm{https}: / / \text { strategimath.blogspot.com }}$ \\
8. & $\underline{\mathrm{https}: / / \text { sinaurajin.blogspot.com }}$ \\
\hline
\end{tabular}



9. $\quad$ https://punnakaryaokee.blogspot.com
10. https://master-ipa.blogspot.com
11. https://inggrisakti.blogsot.com

Pemilihan nama domain blog disesuaikan dengan karakteristik materi yang diajar oleh guru. Berikut adalah contoh tampilan blog pembelajaran yang dihasilkan guru setelah mengikuti pelatihan.

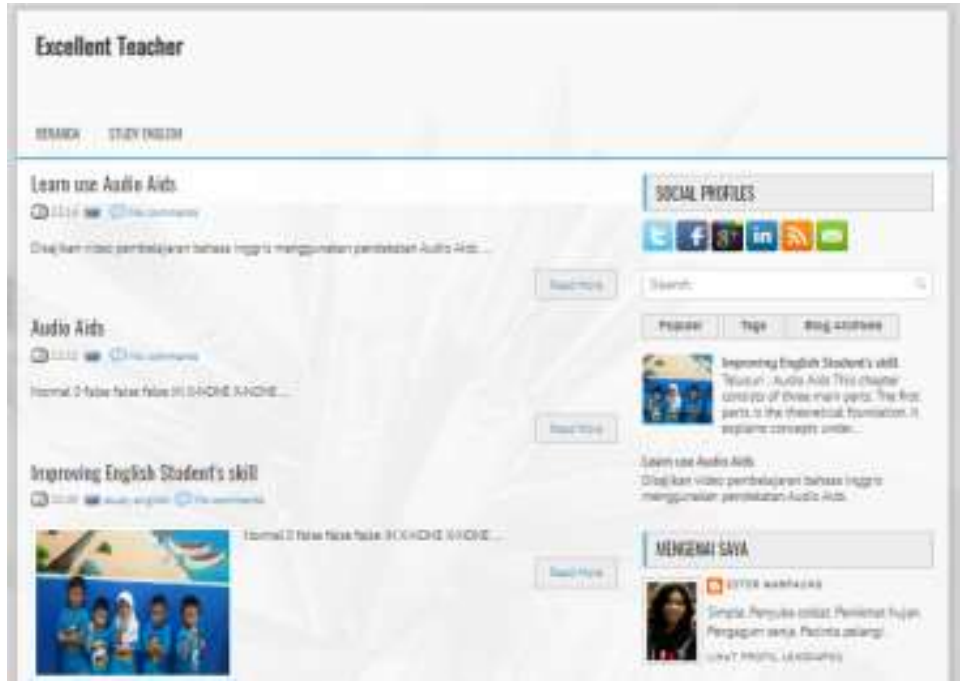

Gambar 2. Tampilan Blog Pembelajaran

Di akhir kegiatan pengabdian kepada masyarakat, dilkukan evaluasi untuk mengetahui tingkat pemahaman guru berkaitan dengan materi yang diberikan serta evaluasi terhadap blog pembelajaran yang dihasilkan guru. Hasil evaluasi pemahaman guru dalam membuat blog pembelajaran dijabarkan pada tabel berikut.

Tabel 2. Persentase Peningkatan Pemahaman Peserta

\begin{tabular}{|c|c|c|c|c|}
\hline Nomor & Materi & Sebelum & Sesudah & $\begin{array}{c}\text { Peningkatan } \\
\text { (\%) }\end{array}$ \\
\hline 1. & memilih nama domain & 35,41 & 70,83 & 50,01 \\
\hline 2. & $\begin{array}{l}\text { memahami fungsi-fungsi operasional } \\
\text { pada blogspot }\end{array}$ & 37,50 & 68,75 & 45,45 \\
\hline 3. & instalasi template & 41,66 & 72,91 & 42,86 \\
\hline 4. & menulis judul artikel & 37,50 & 64,58 & 41,93 \\
\hline 5. & $\begin{array}{l}\text { menjadwalkan penerbitan artikel } \\
\text { secara otomatis }\end{array}$ & 35,41 & 66,66 & 46,88 \\
\hline 6. & mengkategorikan artikel pada label & 37,50 & 66,66 & 43,74 \\
\hline 7. & $\begin{array}{l}\text { menyisipkan gambar dan video } \\
\text { pembelajaran pada artikel }\end{array}$ & 39,58 & 75,00 & 47,23 \\
\hline 8. & $\begin{array}{l}\text { menautkan antarartikel dalam satu } \\
\text { blog }\end{array}$ & 37,50 & 72,91 & 48,57 \\
\hline 9. & $\begin{array}{l}\text { menautkan antarartikel dalam blog } \\
\text { yang berbeda }\end{array}$ & 35,41 & 68,75 & 48,49 \\
\hline
\end{tabular}

Berdasarkan data tabel 2 rata-rata pemahaman guru dalam membuat blog pembelajaran sebelum dilakukan pelatihan sebesar 37,49. Setelah dilakukan pelatihan pembuatan blog pembelajaran, nilai pemahaman guru menjadi 69,67. Artinya secara klasikal, setelah diberikan 
pelatihan terjadi peningkatan pemahaman pembuatan blog sebesar 85,80\%. Secara umum grafik peningkatan tiap aspek digambarkan dalam gambar di bawah ini.

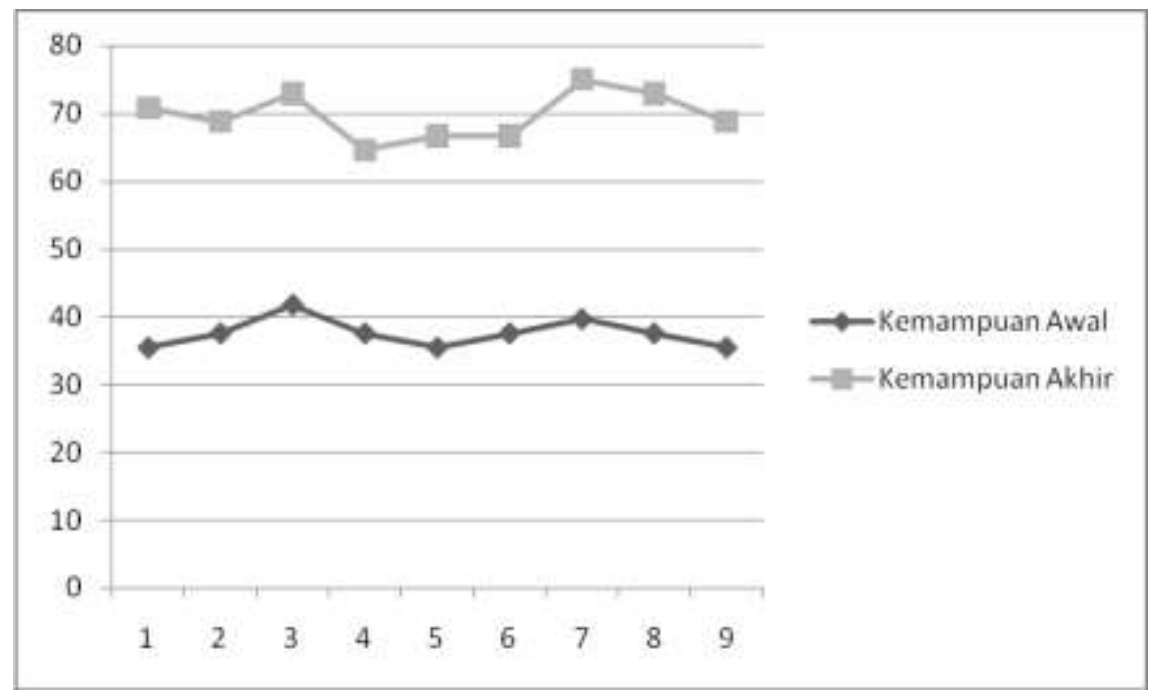

Gambar 3. Data Kemampuan Awal dan Kemampuan Akhir Membuat Blog

Secara kualitatif, hasil pengabdian kepada masyarakat dapat dilihat dari blog pembelajaran yang dibuat oleh guru. Indikator kualitatif yang digunakan meliputi aspek isi, navigasi, dan design interface. Dari segi isi, jumlahnya masih terbatas, berkisar tiga sampai lima artikel tiap blog. Jumlah kata dalam tiap artikel cukup bervariasi antara seratus sampai tiga ratus suku kata. Beberapa blog sudah memiliki navigasi atau menu yang dapat memudahkan pengunjung berselancar dalam blog. Sebagian lain, navigasi blog masih belum tertata dengan baik sehingga banyak navigasi yang belum berfungsi ketika dibuka. Sementara itu, design interface secara umum sudah menarik untuk dilihat. Tampilan template dua kolom dengan sisi kiri untuk menampilkan artikel dan sisi kanan untuk menampilkan widget sangat menarik untuk dilihat. Meskipun demikian, beberapa blog belum diatur agar mobile friendly atau tampilan untuk handphone. Blog yang belum diatur mobile friendly, tampilannya menjadi kurang menarik ketika dibuka melalui handphone atau berbeda ketika dibuka melalui komputer. Berikut disajikan perbedaan blog yang mobile friendly dan belum mobile friendly. Gambar kiri adalah tampilan blog yang mobile friendly, sedangkan gambar kanan adalah tampilan blog yang belum mobile friendly.
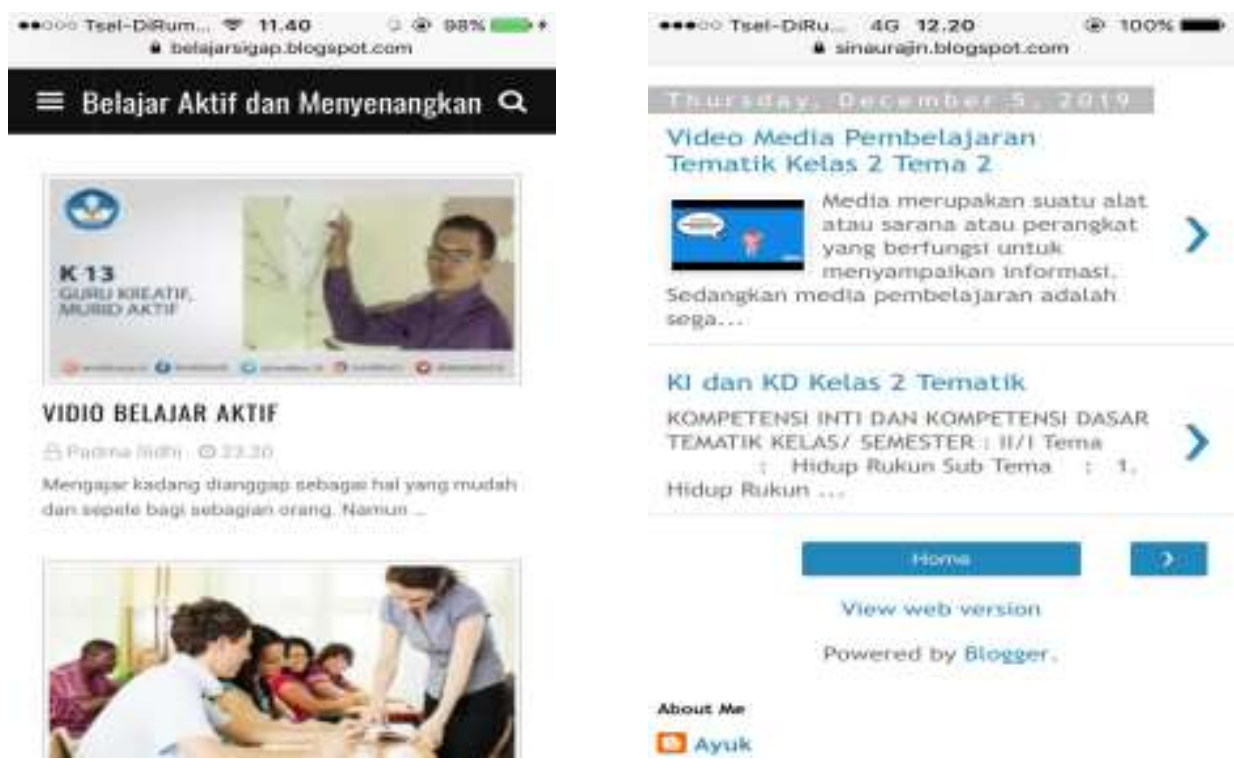

Gambar 4. Perbadingan Interface Blog 
Pihak sekolah sangat mendukung pelaksanaan pengabdian kepada masyarakat. Bentuk dukungan yang diberikan antara lain memberikan izin pelaksanaan, menyediakan sarana dan prasarana, dan membantu koordinasi dengan guru sebagai peserta kegiatan. Secara umum pelaksanaan pengabdian kepada masyarakat di SD Punna Karya tidak mengalami hambatan yang berarti. Beberapa kendala yang dialami dalam pelaksanaan pengabdian kepada masyarakat antara lain kompetensi awal guru dalam membuat blog beragam dan koneksi internet yang kurang baik. Kondisi tersebut membuat penulis harus memberikan pemahaman serta mengenalkan teknik blogging dari awal. Namun, hal itu dapat teratasi karena jumlah peserta yang relatif sedikit sehingga penulis bisa memberikan bimbingan satu per satu secara intensif. Sementara kendala koneksi internet dapat diatasi dengan menggunakan bantuan theatering wifi dari handphone.

\section{KESIMPULAN}

Simpulan hasil pengabdian kepada masyarat ini antara lain: (1) setelah diberikan pelatihan terjadi peningkatan pemahaman pembuatan blog sebesar 85,80\% dan (2) secara kualitatif blog pembelajaran yang dihasilkan guru sudah cukup baik, namun masih terdapat kekurangan baik dari sisi desain interface, navigasi, maupun isinya. Pelaksanaan pengabdian kepada masyarakat ini merupakan langkah awal untuk mengenalkan blog sebagai media pembelajaran kepada guru SD Punna Karya. Oleh karena itu, pelaksanaan pengabdian kepada masyarakat ini dapat dikembangkan lagi dalam bentuk pelatihan lanjutan sehingga pemahaman guru mengenai blog lebih komprehensif.

\section{UCAPAN TERIMA KASIH}

Penulis mengucapkan terima kasih kepada Sekolah Tinggi Agama Buddha Negeri Sriwijaya yang telah memberi dukungan finansial terhadap pengabdian kepada masyarakat ini. Ucapan terima kasih juga penulis ucapkan kepada Kepala SD Punna Karya yang telah memfasilitasi penulis hingga terlaksananya pengabdian kepada masyarakat ini. Penulis juga mengucapkan terima kasih kepada guru SD Punna Karya yang berkenan menjadi peserta pengabdian kepada masyarakat.

\section{DAFTAR PUSTAKA}

Djamarah, S. Bahri dan Aswan Zain. (2006). Strategi Belajar Mengajar. Jakarta: Rineka Cipta.

Hammudin, Budianto dkk. (2017). Pendampingan Pembuatan Student's Blog sebagai Media Pembelajaran Bahasa Inggris. Jurnal Dinamisia, Vol. I Nomor 1 Tahun 2017: 54-60.

Hasan, Husni, Aulia Rahman, dan Madhan Anis. (2017). Pelatihan Pembuatan Blog Sebagai Media Pembelajaran bagi Guru Sejarah di SMA Negeri 1 dan SMA Negeri 3 Langsa. Jurnal Vokasi, Vol 1 No.2 Oktober 2017: 98-103.

Munadi, Yudhi. (2013). Media Pembelajaran Sebuah Pendekatan Baru. Jakarta: Gaung Persada Press.

Pujiastutik, Hernik. 2019. Efektivitas Penggunaan Media Pembelajaran E-learning Berbasis Web pada Mata Kuliah Belajar Pembelajaran terhadap Hasil Belajar Mahasiswa. Jurnal Teladan Volume 4 No.1, Mei 2019: 25-35.

Rahman, S., Wahid Munawar, dan Ega T. Berman. (2014). Pemanfaatan Media Pembelajaran Berbasis Website pada Proses Pembelajaran Produktif di SMK. Jurnal of Mechanical Enginering Education Vol. 1 No.1 Juni 2014: 137-145.

Sartono. (2016). Pemanfaatan Blog sebagai Media Pembelajaran Alternatif di Sekolah. Jurnal Transformatika, Volume 12 , Nomer 1, Maret 2016: 121-134.

Suntoro. (2019). Literasi Informasi Guru Pendidikan Agama Buddha dan Impilkasinya dalam Pembelajaran. Jurnal Refleksi Edukatika, Vol. 9 Nomor 2, Juni 2019: 182-191. 
Supriyono, Heru dkk. (2015). Pelatihan Pengembangan Media Pembelajaran Berbasis Web Bagi Guru SMP dan SMA Muhammadiyah Kartasura. WARTA, Vol. 18, No.2, September 2015: 98 109.

Taufik, Muhammad dkk. (2018). Pelatihan Media Pembelajaran Berbasis Web kepada Guru IPA SMP Kota Mataram. Jurnal Pendidikan dan Pengabdian Masyarakat, Vol. 1 No. 1, Februari 2018: 77-81. 